\title{
Chemical Studies and Antibacterial Activity of the Root of Rumex abyssinicus
}

\section{Sisay Awoke* and Chalachew Gedamu}

Department of Chemistry, College of Natural Sciences, Wollo University, Ethiopia

*Corresponding author e-mail: sisay.awoke@wu.edu.et

\begin{abstract}
One of the Ethiopian endemic plants used traditionally as medicine for different diseases is Rumex abyssinicus. It is widely known as 'Meqmeqo' in Amharic. The aim of this study was to isolate and characterize compounds from the root of $R$. abyssinicus and to test their bioactivities of solvent fractions of the extract. The crude extract was extracted from dried powdered root of the plant with methanol. Then it was fractionated with n-hexane and ethyl acetate with increasing polarity. The yellow powder obtained from ethyl acetate fractionation was applied to column chromatographic separation that led to the isolation of two compounds, diisobutyl phthalate and emodine. Finally, antibacterial evaluation of the ethyl acetate and methanol soluble portions were carried out against four pathogenic bacteria. Both methanol and ethyl acetate soluble portions inhibited all selected bacterial in better at high concentrations.
\end{abstract}

\section{Introduction}

According to World Health Organization (WHO), traditional medicine is defined as the sum total of all knowledge and practice, in the diagnosis, prevention and elimination of physical, mental or social unbalances. These practical experiences and observations are being transferred from generation to generation, either verbally or in writing. According to WHO, about $85 \%$ of world population uses herbal medicines for

Received: June 17, 2020; Accepted: July 9, 2020

Keywords and phrases: Rumex abyssinicus, emodin, diisobutylphthalate, antibacterial activity.

Copyright ( $) 2020$ Sisay Awoke and Chalachew Gedamu. This is an open access article distributed under the Creative Commons Attribution License, which permits unrestricted use, distribution, and reproduction in any medium, provided the original work is properly cited. 
prevention and treatment of diseases. Approximately $20 \%$ of known plants have been used in pharmaceutical studies, affecting the healthcare system in positive ways such as treating cancer and harmful diseases [1].

Plants are rich in many bioactive compounds. High concentrations of phytochemicals, which may protect against free radical, mostly accumulated in fruits and vegetables [2]. Plants have a long history of use on the African continent for the treatment of different diseases and complaints. In certain African countries, up to $90 \%$ of the population still relies exclusively on plants as a source of medicines [3].

Ethiopia has about 800 species of plants that are used in the traditional health care system to treat mental and physical disorders. Traditional medicine remains the main resource for a large majority (80\%) of the people in Ethiopia for treating health problems [4]. Ethiopia is endowed with a diverse biological resources including about 6,500 species of higher plants, with approximately $12 \%$ endemic, hence making it one of the six plant biodiversity rich regions [5]. One of the endemic plants in Africa that is used traditionally as medicine for different diseases is $R$. abyssinicus. It is a perennial weed plant in the family Polygonaceae. It grows in tropical Africa, particularly in central and Eastern Africa, more commonly in cultivated lands. It is widely known as meqmeqo in Ethiopia [6].

$R$. abyssinicus is widely used in folklore medicine for treatment of headache, hemorrhoid, ascaris, scabies, leprosy, fungal skin infection, wounds, eczema, and sore throat and to control mild forms of diabetes. The decoction of the root or leaf powder of the plant is used as vermifuge. Studies have also shown its effect against leukemia cells by initiating cell death through apoptosis [7].

Even though the plant's secondary metabolites have different antimicrobial effects, isolation of the compound, structural elucidation and identification of this plant is not yet exhaustively done [8]. Considering the few available phytochemical study on the plant, the current project is designed to carry out exhaustive phytochemical investigation of Rumex abyssinicus so as to identify bioactive chemical constituents of the plant.

To the best our knowledge, no more studies were conducted in Rumex abysinicus, which grows in Dessie, Ethiopia. This research is an attempt to isolate and characterize further compounds and bioactivity tests from the root of Rumex abyssinicus. 


\section{Materials and Methods}

\subsection{Chemicals and apparatus}

The following materials and instruments were used during the experiment: UV lamp, (long wave (365) and short wave (254) radiation), ${ }^{1} \mathrm{H}$ and ${ }^{13} \mathrm{C}-\mathrm{NMR}$ spectroscopy (Bruker ACQ 400 AVANCE operating 400mHz), IR (Derkin-ElmerBX Spectrometer $\left(400-4000 \mathrm{~cm}^{-1}\right)$ in $\left.\mathrm{KBr}\right)$, column chromatography (CC 34/35) to isolate compounds from the crude extract, thin layer chromatography (TLC 20x5cm) made from pre-coated silica gel on alumina for isolation, TLC glass chamber, Test tubes, funnels, beakers, filter paper, hot plates, oven, rotary evaporator attached with vacuum (model: YC7124, China), electronic balance (1810-BA Model, China), grinder, water bath (Re201BL, Model Indian), Petri dish, micropipettes (different size), thermometer, aluminum foil, measuring cylinder, refrigerator (Samsung model RT34SUMG, Thailand), incubator (DHP-9052B Model), separatory funnel, stand with clamps, stick swab, McFarland densitometer (Den-18 MC model), water distiller and sterilizer. The chemicals used for phytochemical screening were analytical reagents (AR). These include $\mathrm{FeCl}_{3}, \mathrm{CHCl}_{3}$, $\mathrm{HCl}$, lead acetate, $\mathrm{H}_{2} \mathrm{SO}_{4}$, benzene, picric acid, $\mathrm{KOH}$, Dimethylsulphoxide (DMSO), aniline and absolute ethanol. The organic solvents used during the extraction experiments were petroleum ether, n-hexane, ethyl acetate, diethyl ether, acetone and methanol.

\subsection{Collection of plant material, preparation and extraction}

The fresh plant material was collected from Dessie area, south Wollo Zone, about $419 \mathrm{~km}$ away from Addis Ababa, on December 2018. The collected root parts of R. abyssinicus (about $0.4 \mathrm{~kg}$ ) were chopped into smaller pieces and shade dried in an open air at room temperature without any exposure to direct sun light. The dried plant materials were powdered and stored in suitable container until used for extraction as shown in Figure 1. Extraction of the plant material was done using maceration technique. $400 \mathrm{~g}$ of dried powdered root of the plant material was soaked with $1.5 \mathrm{~L}$ methanol for 72 hours with continuous shaking. The extracts were filtered first through a fresh cotton plug and then through Whatmann filter paper (No.1). The filtrate was concentrated by evaporation under reduced pressure using Rotary evaporator at $40^{\circ} \mathrm{C}$ to give dark brown gel like crude extract. The resulting semidried extract was then stored in refrigerator below $4^{\circ} \mathrm{C}$ until used for isolation and the preliminary phytochemical analysis. 

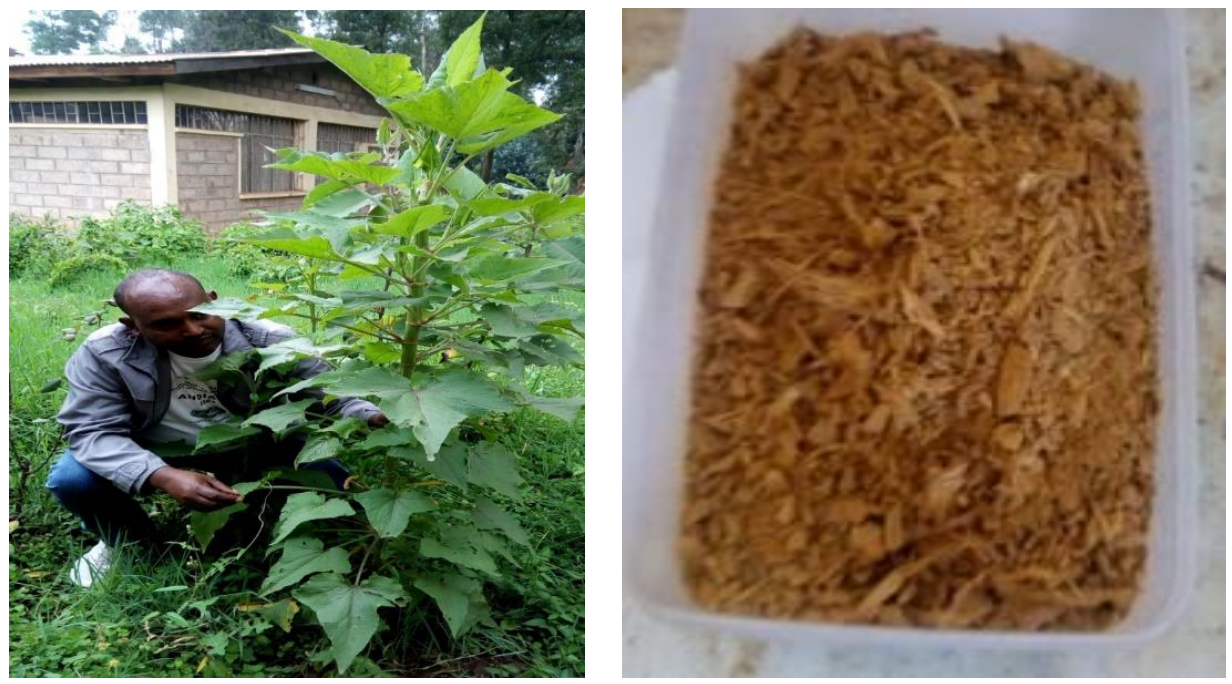

Figure 1. Photographs showing the plant $R$. abyssinicus and powder of root (Chalachew [26]).

\subsection{Phytochemical screening}

Detections of common secondary metabolites were performed for methanol leaves extract of $R$. abyssinicus using the preceding analytical procedures for steroids (Salkowski test) [9], flavonoids [10], terpenoids [11], tannins [12], saponins [10], glycoside [13], alkaloids (Hager's test) [14], phenols [11], quinnones [15] and anthraquinones (Borntrager's test) [16].

\subsection{Fractionation, isolation and characterization of compounds}

The crude was fractionated by separatory funnel using non-polar and polar solvents, n-hexane and ethyl acetate solvents based on increasing polarity. To do solvent fractionation, $100 \mathrm{ml} \mathrm{n}$-hexane was added in to $20 \mathrm{~g}$ of crude extract. The mixture (extract and solvent) was added in to $250 \mathrm{~mL}$ separatory funnel and shaken gently to mix and then allowed to settle for some times until it forms two layers (by placing it on the stand for $24 \mathrm{~h}$ ). The $\mathrm{n}$-hexane soluble portion was collected in a separate flask and concentrated by using a rotary evaporator. It was then placed into open air until dried and weighed. $100 \mathrm{~mL}$ ethyl acetate was added into the remaining marc in the separatory funnel, and mixed thoroughly. After settling for $24 \mathrm{~h}$, the mixture was separated into two layers. The ethyl acetate soluble portion was collected in flask. The separated ethyl acetate portions were then taken to a rotary evaporator to be concentrated. The filtrate 
was placed in an open air until dried and weighed. Finally, the methanol soluble portion, which remained in the funnel, was collected in flask and taken to a rotary evaporator to be concentrated. The filtrate was placed in an open air until dried and weighed. Finally, $0.5 \mathrm{~g}$ n-hexane, $1 \mathrm{~g}$ ethyl acetate soluble portion and $1 \mathrm{~g}$ methanol soluble portions were taken to biology department of Wollo University for antibacterial test. When the TLC of ethyl acetate soluble portion and the methanol soluble portion was done, the ethyl acetate soluble portion has shown promising and well separated chromatograms (spots). As a result, $2.4 \mathrm{~g}$ ethyl acetate soluble portion was taken to column chromatography for further fractionation. Column chromatography technique was applied to isolate two pure compounds, Compound $\mathbf{1}$ and Compound 2.

\subsection{In vitro antibacterial activity test}

\subsubsection{Test organisms}

Four pathogenic microorganisms were selected for the present investigation. These were two gram-positive namely Staphylococcus aureus and Listeria Monocytogenes and two gram-negative Klebsiella pneumonia and Escherichia coli. These four organisms were obtained from the Amhara Public Health Institute - Dessie Branch Clinical Bacteriology and Mycology Laboratory, Dessie City, Ethiopia. The organisms were subcultured in nutrient agar plates and stored in nutrient agar slants at $4{ }^{\circ} \mathrm{C}$ until needed for use.

\subsubsection{Media preparation}

$38 \mathrm{mg}$ of MHA powder was added into $1 \mathrm{~L}$ of distilled water in a flat-bottomed conical flask. To dissolve the media completely, the mixture was heated with frequent agitation until clear solution was observed. The flask was then tightly closed using cotton wool and further covered with aluminum foil. The mixture was autoclaved for $15 \mathrm{~min}$ at $121^{\circ} \mathrm{C}$ after which it was left to cool down to room temperature. $70 \mathrm{~mL}$ freshly prepared sterile MHA medium was poured into $150 \mathrm{~mm}$ diameter Petri dishes. The Petri dishes containing the media were then placed in a sterile in properly adjusted refrigerator until bacteria inoculums were spread on them [17].

2.5.3. Preparation of working solution

Crude extracts and solvent fractions $(0.5 \mathrm{~g})$ were dissolved in Dimethylsulphoxide (DMSO) until the volume of a solution became $1 \mathrm{~mL}$ to get $0.5 \mathrm{~g} / \mathrm{mL}$ stock solutions. 
Different concentrations of extracts $(100,50,10 \mathrm{mg} / \mathrm{mL})$ were prepared after dilution of the stock solution with DMSO.

\subsubsection{Determination of inhibition zone}

Fresh culture bacteria were suspended into $5 \mathrm{~mL}$ of sterile normal saline water and then turbidity of suspension was adjusted equivalent to 0.5 McFarland standards by reading on McFarland Densitometer instrument. A sterile cotton swab was dipped into adjusted bacterial suspension, rotated gently and pressed firmly on the inside wall of the tube above the fluid level to remove excess inoculums from the cotton swab. The swab was streaked to the entire surface of the MHA plate three times by rotating approximately $60^{\circ} \mathrm{C}$ each time to ensure even distribution of the inoculums. Petri-plates were left for three minutes at room temperature. Sterilized filter papers disk containing different concentration of plant extract were placed on plate containing Muller Hinton Agar [18].

The negative control (10\% DMSO in water) and positive control (chloromophynacol, $1 \mathrm{mg} / \mathrm{mL}$ ) were placed into the labeled agar wells. The plates were placed undisturbed at room temperature for $2 \mathrm{~h}$ and then incubated at $37^{\circ} \mathrm{C}$ for $24 \mathrm{~h}$. All tests were performed in triplicate for each bacterial species. Finally, the diameters of inhibition zones were measured in millimeter using digital meter. The mean zone of inhibition and standard error of the mean (Mean \pm SEM) were calculated for the fractions as well as for standard positive control. The zone of inhibition was analyzed whether the bacteria is resistant or sensitive to the reference of a particular antibiotic and values. The formation of clear inhibition zone around the wells of about $\geq 7 \mathrm{~mm}$ diameters was taken as significant susceptibility measurement [18].

\subsection{Statistical analysis}

The antibacterial activity of the extract data was collected, and then analyzed by using statistical analysis software SPSS ver. 20.0. The differences and response among test bacterial strains were presented by mean \pm standard deviation (SD).

\section{Results and Discussion}

The mass and percentage of the crude obtained from $400 \mathrm{~g}$ root powder of $R$. abyssinicus, 79.3 and 19.8 respectively. 20 gm of the crude was taken and successive fractionations were done by $n$-hexane and ethyl acetate. The mass and the percentage of 
fractionation were analyzed as 3.0, 17.0 and $81.0 \%$ for hexane, ethyl acetate and methanol soluble portions, respectively. This finding is in accordance with previous reports [19]. Since methanol is the solvent with the highest polarity, large amount of extract was obtained

\subsection{Phytochemical screening tests}

Prior to isolation and antibacterial tests, the crude extract was analyzed for its phytochemical constituents. The results of the phytochemical screening are summarized in Table 1.

Table 1. Phytochemical screening test.

\begin{tabular}{cllc}
\hline No. & Phytochemical Test & Observation & Indication \\
\hline 1 & Steroid & Red color & + \\
2 & Flavonoids & Yellow precipitate & + \\
3 & Terpenoids & Greenish color & - \\
4 & Saponins & Stable foam & + \\
5 & Tannins & Blue & + \\
6 & Glycoside & Yellow color & + \\
7 & Phenol & Red color & + \\
8 & Quinnones & Blue color & + \\
9 & Anthraquinones & Pink color & + \\
10 & Alkaloid & Yellow precipitate & + \\
\hline
\end{tabular}

Key: + = present; - = absent

As can be seen in Table $1, R$. abyssinicus is rich in various secondary metabolites, such as alkaloids, flavonoids, tannins, phenol and glycosides. This is in agreement with previous studies $[19,20,21]$. But there was negative result on terpenoids which was in disagreement with the previous report [9]. This may be due to the time in which the plant material was collected or experimental error. In study to assess the total content of secondary metabolites, Abate and Ayalew reported the existence of large amount of alkaloid and the minimum amount of flavonoids and saponins in the root of 
$R$. abysinicus [19]. The authors also reported the presence of phenols, tennis, flavonoids, and glycosides in the methanol extract of the root of $R$. abyssinicus. The extracts of rhizomes of $R$. abyssinicus by $80 \%$ methanol were also reported to contain tannins, saponins, flavonoids and anthraquinones [20, 21].

Alkaloids were reported to have analgesic, diuretic, anti-inflammatory and adapetogenic activities which help to alleviate pains, develop resistance against diseases and endurance against stress [22, 23]. Since the phytochemical findings of the current study on the root of $R$. abyssinicus assured the presence of alkaloids, it is possible to conclude the medicinal value of the plant species since alkaloids are reported to be responsible for the aforementioned medicinal activities. Similar to our phytochemical screening results, tannins, which were known to have physiological astringent properties that hasten wound healing, were reported to be present in $R$. abyssinicus [24]. Tannins also have haemostatic properties [23]. Moreover, the presence of tannins, saponins, flavonoids and anthraquinones makes the plant species to have medicinal values such as anti-oxidant, anti-inflammatory, wound healing, and an antibacterial activity [20, 21].

In their study, Abate and Ayalew also investigated the influence of the polarity of the solvent on the extraction of metabolites [19]. For instance, the highest polar solvents like methanol could extract high polar metabolites. Less and medium polar solvents like n-hexane, ethyl acetate, and chloroform could extract less and medium polar metabolites.

\subsection{Characterization of isolated compounds using spectroscopic technique}

\subsubsection{Characterization of compound $\mathbf{1}$}

The IR spectrum of compound $\mathbf{1}$ showed the absorption bands around 2980 and $2920 \mathrm{~cm}^{-1}$ corresponding $\mathrm{C}-\mathrm{H}$ stretching frequencies of the aromatic and aliphatic groups, respectively. The band approximately at $1670 \mathrm{~cm}^{-1}$ most probably belongs to the carbonyl $(\mathrm{C}=\mathrm{O})$ frequency and the band at $1250 \mathrm{~cm}^{-1}$ showed the $\mathrm{C}-\mathrm{O}$ stretching carbonyl frequency of ester, lastly around $1500 \mathrm{~cm}^{-1}$ belongs to the aromatic ring [25]. The ${ }^{1} \mathrm{H}$ NMR spectrum of this compound (Appendix 1 [26]) looks like a mixture of compounds. This conclusion was made by comparing the ${ }^{1} \mathrm{H}$ NMR spectrum of $\mathbf{1}$ with the ${ }^{1} \mathrm{H}$ NMR data reported in open literature for compounds previously reported from R. abyssinicus. The peak at $\delta 2.5$ can be attributed to solvent (DMSO- $\mathrm{d}_{6}$ ); the doublet 
signal at $\delta 1.00(\mathrm{H}-1)$ can be due to protons of methyl groups with neighboring methine (-CH-) group. The septet like (multiplet) signals at $\delta 2.00(\mathrm{H}-2)$ can then be assigned to a methine group neighboring to the methyl groups. The doublet signal $\delta 3.90(\mathrm{H}-3)$ indicative protons that could be attached with oxygenated carbon with one neighboring proton (- $\mathrm{CH}$ - group assigned as $\mathrm{H}-2$ ). The signal assigned as $\mathrm{H}-2$ (methane proton) is then flanked between methylene and methyl carbons. The multiplet peaks around $\delta 7.75$ (H-6) and $\delta 7.7$ (H-7) can be attributed to protons on aromatic ring. These peaks were selected from the observed ${ }^{1} \mathrm{H}$ NMR spectrum since the peaks were found to be similar to one of the compounds, diisobutylphthalate, reported to be present in $R$. abyssinicus species [25]. The chemical structure of diisobutylphthalate is shown in Figure 2. Comparison of the selected signals with the ${ }^{1} \mathrm{H}$ NMR peaks of the reported structure is tabulated in Table 2. As can be seen in Table 2, there is perfect match between the ${ }^{1} \mathrm{H}$ NMR signals of diisobutylphthalate and the selected peaks from compound 1. This suggests that diisobutylphthalate is one of the components of the mixtures expected to be present in compound $\mathbf{1}$ (Fig. 2).

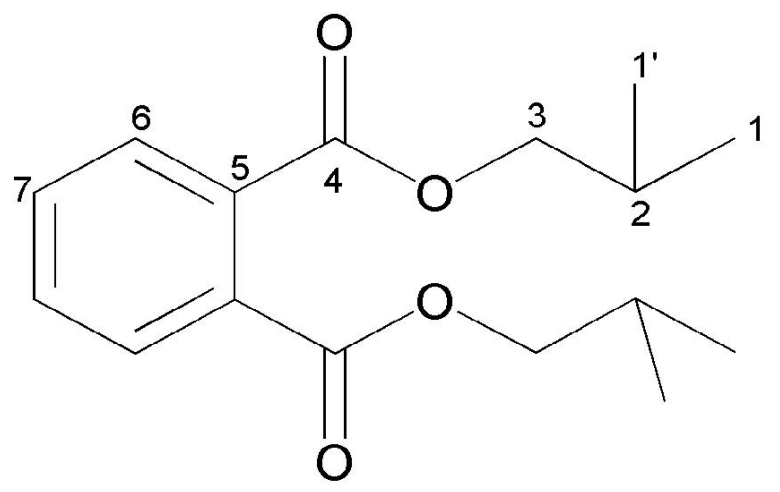

Figure 2. Chemical structure of diisobutylphthalate.

Similarly, comparison was made for ${ }^{13} \mathrm{C}$ NMR signals of compound 1 (Appendix 2 [26]) with the ${ }^{13} \mathrm{C}$ NMR peaks of the reported diisobutylphthalate structure as shown in Table 2. As can be evidenced from the tabulated data, all ${ }^{13} \mathrm{C} N \mathrm{NMR}$ signals of the reported diisophthalate structure is in excellent agreement with selected ${ }^{13} \mathrm{C}$ NMR peaks of 1 . 
Table 2. Comparison of the observed ${ }^{1} \mathrm{H}$ NMR and ${ }^{13} \mathrm{C}$ NMR spectroscopic data (DMSO- $\mathrm{d}_{6}$ ) of $\mathbf{1}$ with reported from the literature ( $\delta$ in ppm).

Carbon

Positions

\section{Compound 1}

Diisophthalate [25]

\begin{tabular}{lcccc}
\hline & ${ }^{1} \mathrm{H} \mathrm{NMR}$ & ${ }^{13} \mathrm{C} \mathrm{NMR}$ & ${ }^{1} \mathrm{H} \mathrm{NMR}$ & ${ }^{13} \mathrm{C}$ NMR \\
$\mathrm{C} 1$ & $1.00 \mathrm{~d}$ & 19.31 & $0.95 \mathrm{~d}$ & 19.30 \\
$\mathrm{C} 2$ & $2,00 \mathrm{~m}$ & 27.66 & $1.95 \mathrm{~m}$ & 27.65 \\
$\mathrm{C} 3$ & $3.90 \mathrm{~d}$ & 71.56 & $4 \mathrm{~d}$ & 71.60 \\
$\mathrm{C} 4$ & - & 167.41 & - & 167.38 \\
$\mathrm{C} 5$ & - & 132.14 & - & 132.11 \\
$\mathrm{C} 6$ & $7.75 \mathrm{~m}$ & 129.13 & $7.74 \mathrm{dd}$ & 129.13 \\
$\mathrm{C} 7$ & $7.70 \mathrm{~m}$ & 132.16 & $7.69 \mathrm{tt}$ & 132.01 \\
\hline
\end{tabular}

The selected ${ }^{13} \mathrm{C}$ NMR signals that perfectly match with the reported signals were then checked in the DEPT spectrum (Appendix 3 [26]) to identify the nature of carbon, i.e., methyl, methylene or methane carbon. As can be seen in Table 2, the nature of carbon perfectly agrees to the carbons of the proposed diisobutylphthalate structure.

In general, the all spectroscopic data analyses and the comparisons of these data with the literature reported data indicate that compound $\mathbf{1}$ is diisobutylphthalate.

In addition to its existence in $R$. abyssinicus, diisobutylphthalate has been known to be present as secondary metabolite in some other plant species. For instance, diisobutylphthalate was separated and identified from the extract of Arum palaestinum, using HPLC and GCMS techniques [27]. However, this compound is not reported as by some other scholars regarding to this plant. This may be raised from paraffin that was used for cover the extracts to avoid further contamination. Then it is not reasonable to report this compound as a constituent of $R$. abyssinicus.

\subsubsection{Characterization of compound 2}

Compound $\mathbf{2}$ was characterized by IR spectroscopy in order to identify the functional groups of the compound. The IR spectrum of 2 (Appendix 5 [26]) showed that the absorption band around $3400 \mathrm{~cm}^{-1}$ corresponding to the stretching vibration peak of the hydroxyl $(\mathrm{OH})$ group. The band around at $2900 \mathrm{~cm}^{-1}$ indicates the $\mathrm{C}-\mathrm{H}$ stretching and the bands approximately at $1670 \mathrm{~cm}^{-1}$ corresponds to unchelated carbonyl of carbon 
$(\mathrm{C}=\mathrm{O})$, and the one around $1650 \mathrm{~cm}^{-1}$ indicates the chelated carbonyl $(\mathrm{C}=\mathrm{O})$ groups. The 2 was also characterized by NMR spectroscopy in order to identify the chemical structure(s) of the compounds present in it. Prior to detail structure elucidation, comparison was made between the NMR data observed for $\mathbf{2}$ with the that of previously reported compounds which were isolated from $R$. abyssinicus. Based on our comparison, ${ }^{1} \mathrm{H}$ NMR spectrum of sample 2 (Appendix 6 [26]) is a mixture of two compounds. One of the components is diisobutylphthalate that has already been found in $\mathbf{1}$. The remaining NMR signals were then compared with the peaks of the reported structures and led us to conclude that the other component is emodine (Figure 3). The ${ }^{1} \mathrm{H}$ NMR spectrum (in DMSO- $\mathrm{d}_{6}$ ) of 2 shows two peaks at $\delta 12.00$ and $\delta 12.20$. These signals can be attributed to the two chelated hydroxyl protons of emodine structure (1-OH and $8-\mathrm{OH})$. The singlet peaks at $\delta 7.10,7.40,7.12$ and $6.56 \mathrm{can}$ be assigned to the four protons of the anthracene ring which are 2-H, 4-H, 5- $\mathrm{H}$ and 7-H, respectively (Figure 3). The intense singlet peak at $\delta 2.40 \mathrm{ppm}$ can be assigned to the methyl group of emodine structure without any ambiguity. The comparison of the ${ }^{1} \mathrm{H}$ NMR signals of $\mathbf{2}$ (after excluding ${ }^{1} \mathrm{H}$ NMR signals of diisobutylphthalate) with the ${ }^{1} \mathrm{H}$ NMR signals of the reported emodine structure is displayed in Table 3.

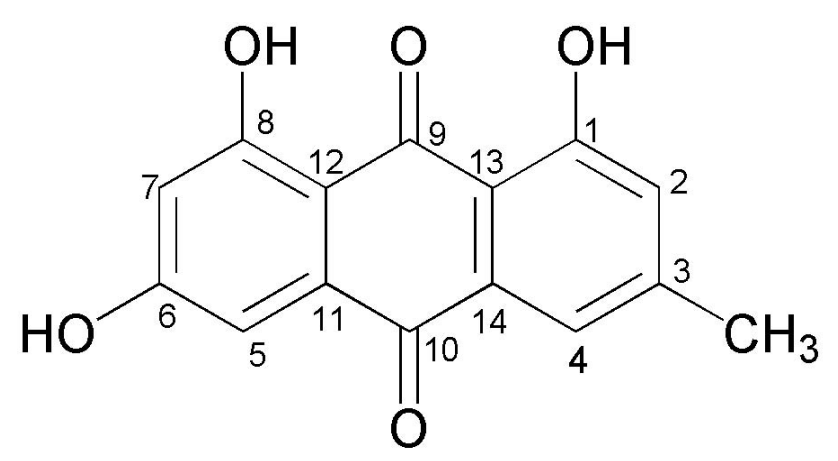

Figure 3. The chemical structure of emodine.

Similarly, comparison was made for ${ }^{13} \mathrm{C}$ NMR signals of compound 2 (Appendix 7 [26]) with the ${ }^{13} \mathrm{C}$ NMR peaks of the reported emodine structure as shown in Table 3. As can be evidenced from the tabulated data, all ${ }^{13} \mathrm{C}$ NMR signals of the reported emodine structure is in excellent agreement with the ${ }^{13} \mathrm{C}$ NMR peaks of compound 2 , after excluding the peaks from diisophthalate structure. 
Table 3. Comparison of the observed ${ }^{1} \mathrm{H}$ NMR and ${ }^{13} \mathrm{C}$ NMR spectroscopic data (DMSO- $\mathrm{d}_{6}$ ) of compound $\mathbf{2}$ and emodine from the literature ( $\delta$ in ppm).

\begin{tabular}{|c|c|c|c|c|}
\hline \multirow{2}{*}{ Carbons } & \multicolumn{2}{|c|}{ Compound 2} & \multicolumn{2}{|c|}{ Emodine [23] } \\
\hline & ${ }^{1}$ H NMR & ${ }^{13}$ C NMR & ${ }^{1}$ H NMR & ${ }^{13} \mathrm{C}$ NMR \\
\hline $\mathrm{C} 1$ & $12.0 \mathrm{~s}(\mathrm{OH})$ & 161.8 & $12.01 \mathrm{~s}(\mathrm{OH})$ & 161.8 \\
\hline $\mathrm{C} 2$ & 7.1 br s & 124.4 & 7.18 br s & 124.4 \\
\hline $\mathrm{C} 3$ & - & 148.5 & - & 148.5 \\
\hline $\mathrm{C} 4$ & 7.40 br s & 120.8 & 7.50 br s & 120.8 \\
\hline $\mathrm{C} 5$ & $7.12 \mathrm{~s}$ & 109.2 & $7.20 \mathrm{~s}$ & 109.2 \\
\hline C6 & $12.02(\mathrm{OH})$ & 165.9 & $12.1(\mathrm{OH})$ & 165.9 \\
\hline $\mathrm{C} 7$ & $6.56 \mathrm{~d}$ & 108.3 & $6.60 \mathrm{~d}$ & 108.2 \\
\hline $\mathrm{C} 8$ & $12.20 \mathrm{~s}(\mathrm{OH})$ & 164.9 & $12.15 \mathrm{~s}(\mathrm{OH})$ & 164.8 \\
\hline C9 & - & 190.0 & - & 189.9 \\
\hline $\mathrm{C} 10$ & - & 181.5 & - & 181.5 \\
\hline $\mathrm{C} 11$ & - & 135.4 & - & 135.3 \\
\hline $\mathrm{C} 12$ & - & 109.3 & - & 109.3 \\
\hline $\mathrm{C} 13$ & - & 113.7 & - & 113.5 \\
\hline $\mathrm{C} 14$ & - & 133.2 & - & 132.9 \\
\hline $3 a-C H$ & $2.40 \mathrm{~s}$ & 21.9 & $2.40 \mathrm{~s}$ & 21.9 \\
\hline
\end{tabular}

The ${ }^{13} \mathrm{C}$ NMR signals that were identified to be the peaks for emodine were then further checked in the DEPT spectrum (Appendix 8 [26]) to crosscheck whether the nature of carbon (methyl, methylene or methane carbon) is in agreement with the proposed structure. As can be seen in Table 3, the nature of carbon perfectly agrees to the carbons of the proposed emodine structure.

The combined spectroscopic data analyses and the comparisons with the literature can then lead us to conclude that compound $\mathbf{2}$ was emodine. From the integration of the ${ }^{1} \mathrm{H}$ NMR signals, it is also possible to conclude that diisobutylpthalate is present as a very minor component with emodine being the major compound. Emodine forms the basis of a purgative anthraquinone derivative and from ancient times, it has been widely used as a laxative compound. It is believed that the presence of hydroxyl groups in position 1 and 8 of the aromatic ring system is essential for the purgative action of this compound [25]. 


\subsection{Antibacterial activity}

After phytochemical screening of the crude extract and further fractionation by different solvents namely n-hexane and ethyl acetate, the ethyl acetate fraction (here referred to as ethyl acetate soluble portion) and the fraction left after n-hexane and ethyl acetate fractionation (here we call it methanol soluble portion) were selected to be investigated for their antibacterial activities. In order to undertake the test, two gramnegative bacteria, E. coli and K. pneumonia, and two gram-positive bacteria, S. aureus and L. monocytogen, were used. The tests were done by preparing three different concentrations for each test. The results of the antibacterial test are summarized in Table 4.

Table 4. The inhibition of methanol and ethyl acetate soluble portions on the selected gram-negative and gram-positive with three concentrations.

\begin{tabular}{|c|c|c|c|c|c|}
\hline \multirow[t]{2}{*}{ Bacteria } & \multirow{2}{*}{$\begin{array}{c}\text { Conc. } \\
(\mathrm{mg} / \mathrm{mL})\end{array}$} & \multicolumn{2}{|c|}{ Mean \% inhibition zone } & \multirow{2}{*}{$\begin{array}{l}\text { Chloromophyna } \\
\text { col (1 mg/mL) }\end{array}$} & \multirow{2}{*}{$\begin{array}{c}\text { DMSO } \\
(3 \%)\end{array}$} \\
\hline & & $\mathrm{MeOH}$ & EtOAc & & \\
\hline \multirow{3}{*}{ E. coli } & 100 & $10 \pm 1.02$ & $12.91 \pm 2.04$ & \multirow{3}{*}{9.45} & \multirow{3}{*}{0} \\
\hline & 50 & $8.05 \pm 0.03$ & $11.25 \pm 2.32$ & & \\
\hline & 10 & & $8.4 \pm 0.34$ & & \\
\hline \multirow{3}{*}{ K. pneumonia } & 100 & $16.53 \pm 1.76$ & $13.43 \pm 1.27$ & \multirow{3}{*}{8.07} & \multirow{3}{*}{0} \\
\hline & 50 & $6.68 \pm 0.31$ & $9.03 \pm 0.64$ & & \\
\hline & 10 & $6.13 \pm 0.66$ & $7.72 \pm 0.36$ & & \\
\hline \multirow{3}{*}{ S. aureus } & 100 & $13.65 \pm 1.74$ & $16.6 \pm 0.08$ & \multirow{3}{*}{9.03} & \multirow{3}{*}{0} \\
\hline & 50 & $8.36 \pm 0.26$ & $11.14 \pm 0.67$ & & \\
\hline & 10 & - & $8.18 \pm 0.10$ & & \\
\hline \multirow{3}{*}{ L. monocytogen } & 100 & $13.16 \pm 0.54$ & $10.8 \pm 0.26$ & \multirow{3}{*}{8.09} & \multirow{3}{*}{0} \\
\hline & 50 & $7.9 \pm 0.45$ & $9.68 \pm 0.47$ & & \\
\hline & 10 & & $8.65 \pm 0.39$ & & \\
\hline
\end{tabular}

According to the reports of Fullas [6], the methanol extract which was applied on E. coli, the gram-negative pathogenic bacteria inhibited $12 \mathrm{~mm}$ and on $S$. aureus it 
inhibited $15 \mathrm{~mm}$. On the other hand, Zelalem and Dula [25] reported that $100 \mathrm{mg} / \mathrm{ml}$ of the methanol extract of root of Rumex abyssinicus on E. coli inhibits $16 \mathrm{~mm}$ diameter. And when it was applied on S. aureus the inhibition zone was $20 \mathrm{~mm}$ [25]. In the current study $100 \mathrm{mg} / \mathrm{mL}$ methanol soluble portion of the crude was applied and the inhibition on average was $10.84 \mathrm{~mm}$ which was less than the reported result $12 \mathrm{~mm}$ by Fullas [6] and $16 \mathrm{~mm}$ reported by Zelalem and Dula [25]. In addition to these the findings of this study shows that the antibacterial test on $S$. aureus by the methanol soluble portion results in on average $13.65 \mathrm{~mm}$ diameter inhibition zone.

As it is shown in Table 4 when $100 \mathrm{mg} / \mathrm{ml}$ of the methanol soluble portion was applied on E. coli the inhibition zone was $10.84 \mathrm{~mm}$ diameter. The same concentration of the ethyl acetate soluble portion was applied on E. coli and $12.91 \mathrm{~mm}$ diameter inhibition, which was better than the methanol soluble portion, was recorded. When the concentration of both soluble portions was decreased to $50 \mathrm{mg} / \mathrm{ml}$, the inhibition zone was decreased to $8.05 \mathrm{~mm}$ and $11.25 \mathrm{~mm}$ respectively. And at $10 \mathrm{mg} / \mathrm{ml} \mathrm{no}$ inhibition was recorded by the methanol soluble portion. But the ethyl acetate soluble portion inhibits $8.4 \mathrm{~mm}$.

$100 \mathrm{mg} / \mathrm{ml}$ methanol soluble portion was applied to anther gram-negative pathogenic bacteria called $K$. pneumonia. Here the inhibition was $16.58 \mathrm{~mm}$, which was very good, result. The same amount of ethyl acetate soluble portion was also inhibited $13.42 \mathrm{~mm}$, which was good. But these results were reduced to $6.98 \mathrm{~mm}$ and $9.03 \mathrm{~mm}$ respectively when the concentrations of the plant extracts were $50 \mathrm{mg} / \mathrm{ml}$. when the concentration decreased to $10 \mathrm{mg} / \mathrm{ml}$ the inhibitions were $6.13 \mathrm{~mm}$ and $7.72 \mathrm{~mm}$ respectively. These results indicate the $K$. pneumonia was resistant at these concentrations. Because if the inhibition zone is less than $8 \mathrm{~mm}$ diameter it is said to be the bacteria is resistant against the antibiotic.

Another finding of this study was the anti-bacterial activity test on two gram-positive pathogenic bacteria $S$. aureus and L. monocytogen. When $100 \mathrm{mg} / \mathrm{ml}$ methanol soluble portion and the same amount of ethyl acetate soluble portion were applied to $S$. aureus separately $13.65 \mathrm{~mm}$ and $16.6 \mathrm{~mm}$ inhibition were measured which was good result. But when the concentrations of the plant materials applied were $50 \mathrm{mg} / \mathrm{ml}$, the results of the inhibition were $8.36 \mathrm{~mm}$ and $11.14 \mathrm{~mm}$ which was weak sensitivity. When $10 \mathrm{mg} / \mathrm{ml}$ of the methanol soluble portion was applied to these bacteria, no inhibition was observed. But the ethyl acetate soluble portion with the same concentration $8.18 \mathrm{~mm}$ diameter was 
recorded. From these results it is possible to conclude $S$. aureus were resistant to the plant material at these concentrations.

The antibacterial test was continued on L. monocytogen. $100 \mathrm{mg} / \mathrm{ml} \mathrm{methanol}$ soluble portion and the same amount of ethyl acetate soluble portion were applied separately on these gram positive bacteria and the results were $13.16 \mathrm{~mm}$ and $10.80 \mathrm{~mm}$ respectively. These results show that the methanol soluble portion was relatively more sensitive than the ethyl soluble portion. Because it maybe $\mathrm{n}$ the methanol soluble portion there were better metabolites against L. monocytogen than the ethyl acetate soluble portions. When the two soluble portions which were applied to the bacteria decreased in concentration to $50 \mathrm{mg} / \mathrm{ml}$ the inhibition recorded were $9.6 \mathrm{~mm}$ and $8.07 \mathrm{~mm}$.

This was weak efficiency. Also no inhibition was observed when $10 \mathrm{mg} / \mathrm{ml}$ methanol and ethyl acetate soluble portions were applied to the bacteria. In general, from the findings of the current study it is possible to conclude that the concentration of the plant material was the main factor for the efficiency of the bacterial inhibition. That means at high concentration of the plant material the efficiency of inhibition was good on the selected bacteria for this study. On the other hands at lower concentration the bacteria were resistant to the plant material.

\section{Conclusion}

In this research, phytochemical screening, isolation and structural elucidation of compounds from root of Rumex abyssinicus were done. The antibacterial activities of methanol and ethyl acetate fractions against selected pathogenic bacteria were also done. From the methanol extracted root of Rumex abyssinicus, 79.3 grams of crude extract was obtained by maceration method. Preliminary phytochemical tests of the current study confirmed the presence of alkaloids, flavonoids, tannins, phenols, glycosides, saponins and anthraquinones.

In this study, two compounds, $\mathbf{1}$ and $\mathbf{2}$, were isolated from ethyl acetate soluble portion of the crude methanol extract root of Rumex abyssinicus. The compounds identified were two natural products namely diisobutyl phthalate and emodin based on spectroscopic analyses and comparison of the NMR data with literature reports. The other findings of this study were in vitro antibacterial activity tests. At $100 \mathrm{mg} / \mathrm{ml}$ concentrations, both methanol and ethyl acetate soluble portions could inhibit all 
selected pathogenic bacteria. But at low concentrations, the selected bacteria were resistant to the plant materials.

When the two soluble portions were compared to each other on their efficiency of their inhibition to the selected gram-positive and gram-negative bacteria, ethyl acetate soluble portion at $100 \mathrm{mg} / \mathrm{ml}$ was more efficient to inhibit E. coli and $S$. aureus than methanol soluble portion at the same concentration and laboratory conditions. But on $K$. pneumonia and L. monocytogen, methanol soluble portion was more sensitive than the ethyl soluble portion at $100 \mathrm{mg} / \mathrm{ml}$ concentration. At $50 \mathrm{mg} / \mathrm{ml}$ concentration, the ethyl acetate soluble portion was more sensitive to all selected gram-negative and grampositive pathogenic bacteria than methanol soluble portion at the same concentration. This may be due to the presence of emodine in ethyl acetate soluble portion.

\section{Data Availability}

All the necessary supplementary data will be made available on request by authors.

\section{Conflicts of Interest}

For this study, the authors received financial and laboratory resources support from Wollo University, and the financial issue is already settled according to the agreement we made with the University. Thus, the authors declare that there is no conflict of interest regarding the publication of this paper.

\section{Funding Statement}

This research was not funded by any funding organization or institution (did not receive specific funding), but was performed as part of the employment of the authors in Wollo University.

\section{Acknowledgements}

Wollo University should be acknowledged for facilitating laboratory equipment and chemicals. Moreover, since this article is part of an M.Sc. Thesis entitled "Phytochemical investigation and antibacterial activity of the root of Rumex abyssinicus", Department of Chemistry should be acknowledged. 


\section{References}

[1] W. Abebe, An overview of Ethiopian traditional medicinal plants used for cancer treatment, European Journal of Medicinal Plants 14(4) (2016), 1-16. https://doi.org/10.9734/EJMP/2016/25670

[2] A. Altemimi, N. Lakhssassi, A. Baharlouei, D. G. Watson and D. A. Lightfoot, Phytochemical: Extraction, isolation, and identification of bioactive compounds from plant extracts, Plants 6 (2017), 42. https://doi.org/10.3390/plants6040042

[3] T. T. Ayele, M. B. Regasa and D. A. Delesa, Antibacterial and antagonistic activity of selected traditional medicinal plants and herbs from East Wollega Zone against clinical isolated human pathogens, Science, Technology and Arts Research Journal 4(3) (2015), 175-179. https://doi.org/10.4314/star.v4i3.26

[4] T. Teklehaymanot, M. Giday, G. Medhin and Y. Mekonnen, Knowledge and use of medicinal plants by people around Debre Libanos monastery in Ethiopia, Journal of Ethnopharmacology 111(2) (2007), 271-283. https://doi.org/10.1016/j.jep.2006.11.019

[5] B. Abera, Medicinal plants used in traditional medicine by Oromo people, Ghimbi District, Southwest Ethiopia, J. Ethnobiology Ethnomedicine 10 (2014), Article No. 40. https://doi.org/10.1186/1746-4269-10-40

[6] F. Fullas, A Short Note on Meqmeqo (Rumex abyssinicus), November 22, 2015. Accessed Available: http://www.ethiomedia.com/aa2nov15/4491.html

[7] N. Worku, A. Mossie, A. Stich, A. Daugschies, S. Trettner, N. Y. A. Hemdan and G. Birkenmeier, Evaluation of the in vitro efficacy of Artemisia annua, Rumex abyssinicus, and Catha edulis Forsk extracts in cancer and Trypanosoma brucei cells, International Scholarly Research Notices 2013, Art. ID 910308, 10 pp.

https://doi.org/10.1155/2013/910308

[8] F. Melkamu, R. Padmanabhan and G. Gurmessa, Phytochemical investigation and in vitro antibacterial evaluation on root extracts of Rumex abyssinicus, Nat. Prod. Chem. Res. 4(6) (2016), 239. https://doi.org/10.4172/2329-6836.1000239

[9] B. S. Joseph, P. H. Kumbhare and M. C. Kale, Preliminary phytochemical screening of selected medicinal plants, Int. Res. J. of Science \& Engineering 1(2) (2013), 55-62.

[10] G. O. de Silva, A. T. Abeysundara and M. M. W. Aponso, Extraction methods, qualitative and quantitative techniques for screening of phytochemical from plants, American Journal of Essential Oils and Natural Products 5(2) (2017), 29-32. 
[11] K. Sahira Banu and L. Cathrine, General techniques involved in phytochemical analysis, International Journal of Advanced Research in Chemical Science 2(4) (2015), 25-32.

[12] A. Z. Yusuf, A. Zakir, Z. Shemau, M. Abdullahi and S. A. Halima, Phytochemical analysis of the methanol leaves extract of Paullinia pinnata linn, J. Pharmacognosy Phytother. 6(2) (2014), 10-16. https://doi.org/10.5897/JPP2013.0299

[13] M. L. Hossain, M. A. A. S. M Hossain, K. K. Sarkar, A. Hossain and M. A. Rahman, Phytochemical screening and the evaluation of the antioxidant, total phenolic content and analgesic properties of the plant Pandnus foetidus (family pandanaceae), Int. Res. J. Pharmacy 4(2) (2013), 170-172.

[14] C. J. Semenya, R. B. Maseko and S. S. Gololo, Comparative qualitative phytochemical analysis of the different parts of Barleria dinteri (Oberm): A contribution to sustainable use of the plant species, Journal of Pharmaceutical, Chemical and Biological Sciences 6(2) (2018), 52-59.

[15] G. Jayapriya and F. G. Shoba, Screening for phytochemical activity of Urechites lutea plant, Asian Journal of Plant Science and Research 4(6) (2014), 20-24.

[16] N. Morsy, Phytochemical analysis of biologically active constituents of medicinal plants, Main Group Chemistry 13 (2014), 7-21. https://doi.org/10.3233/MGC-130117

[17] E. Abebe and N. Mekonnen, In Vitro antibacterial activity of rumex nervosus, plantago lanceolata, solanum incanum and lepidium sativum against selected bacterial pathogens of human and animals, Ethiopian Veterinary Journal 20(2) (2016), 119-131.

[18] Y. Besufekad, S. Beri, T. Adugnaw and K. Beyene, Antibacterial activity of Ethiopian Lepidium sativum $L$. against pathogenic bacteria, Journal of Medicinal Plants Research 12(6) (2018), 64-68. https://doi.org/10.5897/JMPR2017.6321

[19] L. Abate and B. Ayalew, Assessment of total content of secondary metabolites, in vitro free radical scavenging potential and peroxide value on different solvent extracts of Rumex abyssinicus Jacq. root, Journal of Chemical and Pharmaceutical Research 11(2) (2019), 39-46.

[20] E. Mulisa, K. Asres and E. Engidawork, Evaluation of wound healing and antiinflammatory activity of the rhizomes of Rumex abyssinicus J. (Polygonaceae) in mice, BMC Complement Altern. Med. 15 (2015), 341. https://doi.org/10.1186/s12906-015-0878-y

[21] R. W. Bussmann, P. Swartzinsky, A. Worede and P. Evangelista, Plant use in Odo-Bulu and Demaro, Bale region, Ethiopia, J. Ethnobiology Ethnomedicine 7 (2011), 28. https://doi.org/10.1186/1746-4269-7-28 
[22] F. A. Awe, A. O. Giwa-Ajeniya, A. A. Akinyemi and G. N. O. Ezeri, Phytochemical analysis of Acalypha wilkesiana, Leucaena leucocephala, Peperomia pellucida and Senaa alata Leaves, The International Journal of Engineering and Science 2(9) (2013), 41-44.

[23] T. V. Dougnon, J. R. Klotoé, J. Sègbo, J.-M. Atègbo, A. P. Edorh, F. Gbaguidi, A. S. Hounkpatin, C. Dandjesso, L. Fah, B. Fanou, K. Dramane and F. Loko, Evaluation of the phytochemical and hemostatic potential of $J$ atropha multifida sap, African Journal of Pharmacy and Pharmacology 6(26) (2012), 1943-1948.

https://doi.org/10.5897/AJPP12.351

[24] G. Alam, M. P. Singh and A. Singh, Wound healing potential of some medicinal plants, International Journal of Pharmaceutical Sciences Review and Research 9(1) (2011), 136-145.

[25] G. Zelalem and D. Dula, Isolation, characterization and antibacterial activities evaluation of Rumex abyssinicus rootbark extracts, Nat. Prod. Chem. Res. 7(1) (2019), 353. https://doi.org/10.4172/2329-6836.1000353

[26] G. Challachew, Phytochemical investigation and antibacterial activity of the root of Rumex abyssinicus, M.Sc. Thesis, Wollo University, 2019.

[27] A. I. Husein, M. S. Ali-Shtayeh, R. M. Jamous, W. J. Jondi and N. Abd-Aljapar Zatar, Phthalate derivatives are naturally occurring in Arum Palaestinum, Int. J. Curr. Res. Aca. Rev. 2(9) (2014), 195-203. 